\title{
Peer learning in international higher education: the experience of international students in an Irish university
}

\section{Aida Idris, Georgeta Ion \& Aidan Seery}

To cite this article: Aida Idris, Georgeta Ion \& Aidan Seery (2019) Peer learning in international higher education: the experience of international students in an Irish university, Irish Educational Studies, 38:1, 1-24, DOI: 10.1080/03323315.2018.1489299

To link to this article: https://doi.org/10.1080/03323315.2018.1489299

曲 Published online: 27 Jun 2018.

Submit your article to this journal $\widetilde{ }$

Џ Article views: 1153

Q View related articles $\square$

View Crossmark data ¿

Citing articles: 1 View citing articles $\longleftarrow$ 


\title{
Peer learning in international higher education: the experience of international students in an Irish university
}

\author{
Aida Idris ${ }^{\mathrm{a} *}$, Georgeta Ion $^{\mathrm{b}}$ and Aidan Seery ${ }^{\mathrm{c}}$ \\ ${ }^{a}$ Faculty of Business and Accountancy, University of Malaya, Kuala Lumpur, Malaysia; ${ }^{b}$ Facultat \\ de Ciències de l'Educació, Universitat Autonoma de Barcelona, Barcelona, Spain; 'School of \\ Education, Trinity College Dublin, Dublin, Ireland
}

(Received 10 May 2017; accepted 31 May 2018)

\begin{abstract}
Some of the main concerns in international higher education are the feeling of isolation among international students and their inability to adapt to the host environment, which may result in sub-optimal academic performance. Theoretically, peer learning can be an effective method to reduce these problems since it has the capacity to address isolation and adaptability issues among international students in a way that improves their learning experience and outcomes. Given the above, our study was designed to investigate this topic, focusing on the experience of international students. In this exploratory case study of a leading Irish university, we adopted a survey method via questionnaire to quantify and compare the experiences of a sample of international students at the said university. Five aspects of peer learning were explored, namely usage rate, current practices, outcomes, challenges, and coping strategies. We also included an open-ended section in the survey instrument for respondents to offer qualitative suggestions to the host institution. Through methodological triangulation of the quantitative and qualitative data, we discovered diverse practices, challenges, and outcomes of peer learning across different groups of international students in this university. The paper concludes with a discussion of research implications and suggestions for future studies.
\end{abstract}

Keywords: peer learning; international higher education; international students' experience; case study; methodological triangulation

\section{Introduction}

Over the past few decades, international higher education has been changing dramatically and producing unexpected challenges for European universities (Olcott 2009; Teichler 2009). The current trend follows the direction of increasing cross-border education, which has become a major issue in higher education (Teferra and Knight 2008). One important feature of recent student mobility is the decline in numbers travelling to popular destinations, such as the USA, UK, and Germany, and the increase in numbers studying in Asian countries including China, Korea, and Malaysia (OBHE 2013; OECD 2014). This shift in destination choice from east-to-west to east-to-east is a matter of concern in a number of European higher education systems that traditionally were very successful in attracting international students and has led to an

\footnotetext{
*Corresponding author. Email: aida_idris@um.edu.my 
accelerated effort to examine the factors involved in both mobility and the quality of the student experience.

With the UK's exit from the EU triggered by the Brexit referendum in June 2016, there are further uncertainties in student mobility trends. It is possible that future restrictions on free movement or new visa regulations and rising costs in the UK would deter prospective international students from considering British universities as their study destination (Faughey 2016), thus posing new opportunities and challenges for other global universities. Under those circumstances, Ireland could have an increased attraction (Irish Independent 2017; University Times 2017), especially among EU students, since it offers them advantages in terms of a shorter geographical distance and a common currency. Ireland is also now the only nation in the EU which uses English widely; this holds a special significance for most students interested in international higher education.

From a pedagogical point of view, there is still much to be discovered about teaching and learning (T\&L) practices which best serve the needs of international students (Lillyman and Bennett 2014). Learning difficulties faced by international students are diverse, and they may experience stress in the form of what Huang (2012) calls 'learner shock', causing isolation (Erichsen and Bolliger 2011), as well as frustration and anxiety (Yeh and Inose 2003). Bandura's (1977) social learning theory suggests that individuals learn better when they are placed in a learning environment which encourages social exchange and interactions. However, the creation of this environment can be very challenging for teachers and education institutions because of the diversity of the student population itself. Compared to the locals, international students tend to have limited knowledge about the host environment and therefore need greater support to help them adapt more easily and gain a positive learning experience abroad (Bartram 2008; Furnham 2004). When this support comes from their own peers, social learning becomes peer-driven and is heightened (Evans 2015; Jacobs, Hurley, and Unite 2008; McGuire 2006). Since it facilitates the construction of knowledge through active interactions among learners from different backgrounds, peer learning can be an effective T\&L approach in a cross-cultural setting.

Set against the above background, our study was concerned with the peer learning experiences of international students in Ireland. The primary goal of the study was to explore similarities and differences among respondents of different nationalities. We adopted an exploratory case study approach that would allow us to uncover potential issues which could be pursued further in future. A leading public university in Dublin, the capital city of Ireland, was chosen as our case because of the great diversity of its international student population as well as its reputation as an international higher education provider. Through the use of a survey via questionnaire, we quantified and compared the peer learning experiences of a sample of international students at this university. An open-ended section was also included in the survey instrument, where respondents could provide qualitative comments on their peer learning experiences in the said university. Using mixed-method analysis, the resulting quantitative and qualitative data were triangulated to produce the basis of our deductions and recommendations for future research. 


\section{Internationalisation of higher education in Europe}

The European Higher Education system and its internationalisation process as we know it today is the result of the Bologna declaration, which represents the basis of the common pacts and interactions for creating an open and competitive European Higher Education Area (Zgaga 2006, 24). The challenges caused by globalisation and a knowledge-based economy have also been identified within the 'European Area' in a broader political context by the European Union in the Lisbon Strategy of March 2000 (European Commission 2010). The role of internationalisation in the Bologna process can be seen in the creation of a common European space and in its harmonisation. To realise the objective of the strategy, that is to create a competitive knowledge-based society, internationalisation must be directed outwards (from Bologna to other parts of the world), a process normally referred to as external internationalisation (Zgaga 2006).

Current challenges in international higher education lie in the increasingly vocal demand for socially accountable, culturally sensitive, and critical approaches to curriculum, intercultural competencies, transnational literacy, and student support in institutions attracting international students (Hawawini 2011). Consequently, there is a growing number of new types of providers, modes of delivery, programmes, and qualifications, and a changing nature and form of cooperation between higher education institutions (Chapman and Sakamoto 2011; de Wit 2010). These emerging trends in the current environment are raising the bar for higher education providers about their internationalisation readiness, not only in matters such as curriculum design and infrastructure, but also cultural diversity and inclusion.

Particularly for Irish universities, the post-Brexit environment presents fresh opportunities and challenges. While there is a potential gap left by British universities that can be filled, there are worries that the Irish higher education sector might not be adequately prepared to cope with a sudden surge in diversity and the various needs and wants of international students coming from different parts of the world. The former Head of Higher Education Authority, Tom Boland, warns against xenophobia in the Irish higher education environment (University Times 2017), suggesting the importance of developing strategies for an internationalisation approach that is culturally sensitive and inclusive. In T\&L areas, Ireland's strategies to improve readiness for cultural diversity and inclusion may involve the revival of comparative and international education courses for teachers (O'Sullivan 2008), as well as the introduction of cross-cultural management as an explicit and integrated component in all higher education curricula for students (Keane 2009).

A study of Irish international higher education by O'Reilly, Hickey, and Ryan (2013) identified several communication and socio-cultural issues affecting international students' learning experiences. Their paper highlighted the problem faced by many international students in Ireland to communicate in a language which is not their native tongue, an issue often observed elsewhere too (Andrade 2006; Evans and Stevenson 2011; Mittelmeier et al. 2017). A lack of engagement between international and Irish students in T\&L activities has also been observed (Dunne 2013), which according to Naykki et al. (2014) may be due to factors such as differing goals and priorities, communication styles, ways of interpreting a task, etc. The findings made by Dunne (2013) and O'Reilly, Hickey, and Ryan (2013) are useful because they have helped to uncover some key challenges in Ireland's international higher 
education. However, these studies focused on the perspective of local students and managers, while excluding the international student viewpoint, thus leaving a gap to be addressed in the current paper.

\section{Peer learning in the context of international higher education}

The bulk of past research on international students' experiences has examined the reasons students prefer to study overseas, their expectations and needs, and the perceived benefits of international education (Hawawini 2011; Lillyman and Bennett 2014; OBHE 2013; OECD 2014). Extant literature suggests massive opportunities for the student to gain an exciting chance to mix with a wide range of nationalities (Brown and Holloway 2008), increase their level of confidence and responsibility in their own education (Warring 2010), enrich their views and experience personal development as they become independent thinkers and agents for change (Campbell 2010).

However, studying abroad also poses tremendous difficulties for students. When learning takes place in an international context, it typically becomes even more complex due to the new socialisation process that foreign students have to experience when they change their usual learning environment or 'habitus' (Webb, Schirato, and Danaher 2002). Some of the main concerns arising from this are the feeling of isolation among international students and their inability to adapt to the host environment, which may result in sub-optimal academic performance (Erichsen and Bolliger 2011; Huang 2012; Yeh and Inose 2003). To cope with these challenges, international students often rely on other actors in the learning environment, particularly their peers, to improve their knowledge of the environment (Bartram 2008; Campbell 2012).

The advantages of peer learning in higher education can be explained by Bandura's (1977) social learning theory which suggests that students' behavioural and cognitive learning processes become integrated in an environment which encourages social interactions and self-directed learning (Fernández et al. 2015; Hall and Jaugietis 2010; Topping \& Ehly, 2001). This theory views knowledge as socially constructed, resulting from dialogic and interactions between teachers and learners, and amongst learners themselves. From a constructivism point of view (Evans 2015), peer learning articulates mechanisms in which learners internalise knowledge through the accommodation and assimilation processes and construct new knowledge from their experiences. Most peer learning models are based on the concept of collaborative learning guided by behavioural, cognitive and constructive theories (Jacobs, Hurley, and Unite 2008; McGuire 2006).

Cohen, Lotan, and Holthuis (1995) define peer learning as a student-centred T\&L method that facilitates the exchange of knowledge among learners. It departs from traditional approaches which emphasise the superiority of the teacher over students and instead builds on the concept that learning is more effective when knowledge is constructed and shared among peers. From the works of Jacobs, Hurley, and Unite (2008), McGuire (2006), and Parr and Townsend (2002), peer learning can be categorised into three types, as described below:

- peer tutoring - a student is appointed as coach or mentor and shares his/her knowledge with other students by way of formal tutorials. 
- cooperative learning - students work together in small groups on a structured activity and are individually accountable for their work, yet also evaluated as a group; cooperative groups work face-to-face and are usually managed by a leader.

- collaborative learning - students team up in a less structured way to explore a problem statement, bringing complementary skills to the team and offering alternative solutions; individuals in different geographical areas working on an assignment together through the Internet are an example of collaborative learning.

The notion of using peer learning with international students has risen mainly due to the importance of addressing their numerous but unique needs (Williamson and Paulsen-Becejac 2015). Due to the unprecedented increase in student diversity, especially among international students of various nationalities, peer learning has been shown to be cost-effective in catering to their diverse needs without affecting the standards and quality of learning experiences offered by educational institutions (Keenan 2014). Based on the arguments of social learning and constructivism theorists (Bandura 1977; Fernández et al. 2015; Hall and Jaugietis 2010; Topping \& Ehly, 2001), peer learning can be an effective pedagogical approach for international students by facilitating their socialisation and learning processes through peer interactions. With adequate support from local actors, these interactions help international students adapt socially to the host environment and acquire a deeper understanding of learning technologies and techniques which serve them better academically.

Peer learning can also bring huge benefits in a wider context since all students, foreign and local, construct knowledge by engaging with others and taking an active role in learning (Evans 2015). Interactions with peers of different nationalities increase students' knowledge of global issues and present them with an opportunity to benefit from cultural experiences that they might less likely gain from an allhome student group (Dunne 2013). Diversity contributes to the learning contexts and adds fresh viewpoints during a classroom discourse (Charles-Toussaint and Crowson 2010; Lee and Rice 2007). Cantor (2004) argued that when diversity brings various perspectives to a given dialogue, it enables students to identify new possibilities for both themselves and their environment.

\section{Methodology}

This study is the first in a series of research that we are conducting on the topic of peer learning in international higher education. Ultimately our goal is to compare data obtained from leading universities in different parts of the world, which will enable us to derive conclusions based on similarities and differences in the learning habitus. In the current study, we adopted an exploratory case-based approach to help us uncover potential issues which can be pursued further in latter research. A leading public university in Ireland was selected as our host institution due to its strong reputation in higher education (QS World University Rankings 2016/2017) and the rich diversity of its international student population. Here we define international students as those with a foreign citizenship or nationality, while local students are defined as Irish citizens consisting of majority White Irish and other minority 
ethnic or cultural groups such as Asian Irish, Black Irish, and Irish Traveller (Central Statistics Office 2016).

According to the university's website, its total number of students is approximately 17,000; a quarter of them are foreign nationals, originating from over 120 countries and spread across a wide spectrum of disciplines. The university itself is situated in the heart of Dublin, the capital city and global commercial centre of Ireland, which has seen an increase of almost $20 \%$ in international student enrolment in public universities from 2016 to 2017 (Irish Independent 2017). Local students at this university come from all over the country, which has a population of 4.8 million, comprising $79.2 \%$ White Irish, and $21.8 \%$ minority groups (Central Statistics Office 2016). With the exception of Linguistics courses, most degree programmes offered by this university are conducted in English. Student assessment is broadly categorised into two types: continuous assignments and final examinations. While final examinations mainly assess students' individual performance, continuous assignments evaluate their teamwork and group output, involving a high level of peer learning.

Our study began with research design. The ensuing sampling process was arduous and took almost six months to complete, upon which the initial design had to be revised. After submitting a proposal to the university's research ethics committee and getting their approval, we proceeded with data collection. Since both quantitative and qualitative data were collected, we first analysed each set of findings separately and later integrated them using methodological triangulation. Below we describe in greater detail aspects of this study from research design and sampling, to data collection and data analysis.

\section{Research design and sampling}

Since this was an exploratory case study, we began our study by consulting the opinion of peer learning experts in this institution. A number of professors actively involved in student peer learning activities were contacted through email, out of which two responded, agreeing to be interviewed. Our consultation with the two experts helped to narrow down our scope to five elements of peer learning from the perspective of international students in this university, namely (1) the rate of peer learning usage, (2) current practices in peer learning, (3) outcomes of peer learning, (4) challenges in peer learning, and (5) strategies to cope with those said challenges.

We then considered a combination of approaches to gather data from a sample of international students in this institution, namely personal interviews, focus group discussion, and survey through a questionnaire (Cohen, Manion, and Morison 2000). These approaches would have enabled us to gather, first, qualitative data for identifying recurring themes, and second, quantitative data for measuring the level of occurrence. All international student bodies registered with the university were contacted via email to solicit participation for each of the three data collection approaches proposed earlier. Unfortunately, the response was dismal and we had to revise our technique to convenience sampling. Some international student representatives were approached in person during events such as conferences and seminars; yet again with a very little result. Eventually, through word-of-mouth, we were able to locate three international students who were prepared to assist in data collection. The first was a German volunteer at the university's international student centre, second a Malaysian residing in the student accommodation hall, and the last was Saudi 
Arabian and a member of the Muslim students association at this university. Based on their input, we concluded that personal interviews and focus group discussions were not popular among our target respondents because of their lengthy and personal nature. Hence to increase the rate of student participation, we decided to proceed with only a survey through a questionnaire, which could also be easily replicated for our future studies.

We then self-developed a questionnaire guided by the conceptual works of Jacobs, Hurley, and Unite (2008), McGuire (2006) and Parr and Townsend (2002), as well as the advice given by the two experts mentioned earlier. For each of the five elements of peer learning that were to be examined, we posed a list of close-ended statements with a Likert scale located next to each statement. Each scale consisted of five values whereby $1=$ Strongly Disagree, $2=$ Disagree, $3=$ Unsure, $4=$ Agree, and $5=$ Strongly Agree. Participants of the survey were required to respond by circling the appropriate value which represented the extent to which they agreed or disagreed with a particular statement. In the Demographics section of the questionnaire, they were asked to provide information on their nationality, gender, degree programme, level of study in the programme, language of instruction, and student status at the university. Following the recommendations of our three international student contacts, questions of a more personal nature, such as age, family background, and financial situation, were excluded.

The draft questionnaire was then referred back for comments to the two professors we had met earlier. Both experts suggested that a definition of peer learning be included to ensure that all participants would have a correct and common understanding of the concept. Subsequently, in the revised draft of the questionnaire, the definition of peer learning derived from Cohen, Lotan, and Holthuis (1995) was provided. Moreover, there are three different types of peer learning, namely peer tutoring, cooperative learning, and collaborative learning (Parr and Townsend 2002), which do not necessarily enjoy the same rate of implementation at any given habitus. Thus, changes were made to the usage rate section so that each type of peer learning could be measured explicitly. The scale used for usage rate measurement was $1=$ Never Used, 2 $=$ Rarely Used, 3 = Moderately Used, $4=$ Often Used, $5=$ Always Used. Respondents were asked to give a score for each of the three types of peer learning based on their actual learning experiences and practices in this university, instead of their perception of the extent of its usage.

Although a close-ended questionnaire with Likert scale produces data which are more easily quantified and analysed mathematically, its ability to gather in-depth information and expose unforeseen trends is limited (Bryant 2011; IES 2015). To address this problem, we included another section in the questionnaire which would allow the respondents to give open-ended qualitative comments on their peer learning experience at this university. This part of the questionnaire was designed to welcome suggestions from the respondents on how peer learning can be improved by the host institution to enhance their overall international education experience.

\section{Data collection}

Since international students in this university have come from a large number of countries and enrolled in a wide range of disciplines, our research population had to reflect that heterogeneity. We targeted international students, both full-time and 
exchange, of various nationalities, programmes, and levels of study. However, only undergraduate students were chosen because postgraduate students in this institution have a flexible work schedule and are therefore very difficult to access. Additionally, we also limited our sample of exchange students to those who were visiting for at least two semesters so that their learning experience in this university would be comparable to that of the first-year full-time students.

As mentioned earlier, data collection was based on convenience sampling. Our three international student enumerators would only accept a maximum of 50 survey forms each, resulting in a total of 150 forms being distributed evenly at three locations in the university: international student centre, student residence hall, and Muslim students association. We allocated one month for data collection, at the end of which 73 usable forms were returned (48.7\% response rate). A profile of the respondents was generated through frequency analysis, as shown in Table 1.

Since the number of respondents was small and thinly spread, some of their demographic characteristics had to be re-categorised more broadly for the purpose of our analysis later. Thus, we made the following three data conversions: (1) nationality to continent, (2) individual programmes to 'Sciences' versus 'Arts, Humanities and Social Sciences', and (3) level of study to 'Juniors' (first or second year) versus 'Seniors' (third year and above). Using these broad categories, we summarise the respondents' profile as follows: $19(26.0 \%)$ were Europeans, $16(21.9 \%)$ North Americans, and $38(52.1 \%)$ were Asians. 18 (24.7\%) of them were male and the remaining 55 $(75.3 \%)$ were female. $44(60.3 \%)$ had enrolled in Science programmes, and the other 29 (39.7\%) were in Arts, Humanities, and Social Sciences. 46 (63.0\%) were junior students while the other $27(37.0 \%)$ were seniors. Full-time students comprised $61(83.6 \%)$ of the total sample, while the other $12(16.4 \%)$ were exchange or visiting students. All $73(100.0 \%)$ respondents reported English as the language of instruction used in their programme.

\section{Data analysis}

Three stages of data analysis were conducted: median analysis for the overall sample and sub-samples, thematic analysis of the open-ended suggestions for improvement, and methodological triangulation of the quantitative and qualitative data.

The median is the value separating the higher half of a data sample, a population, or a probability distribution, from the lower half (Burns 2000). For a data set, it may be thought of as the 'middle' value. The basic advantage of the median in describing data compared to the mean (often simply described as the 'average') is that it is not skewed so much by extremely large or small values, and so it may give a better idea of a 'typical' value. Because of this, the median is of central importance in robust statistics, as it is the most resistant statistic.

In this study, median values were calculated using the Statistical Package for Social Sciences (SPSS). The overall medians enabled us to determine general patterns in the respondents' experience of peer learning usage, practices, outcomes, challenges, and coping strategies in their respective programmes. On the other hand, median value comparisons helped us to distinguish trends among different groups of international students. At this point, it must be recalled that our original objective was to compare students of various nationalities. However, since the sample was small and thinly distributed, we had to re-categorise our respondents based on the continent; 
Table 1. Profile of respondents.

\begin{tabular}{|c|c|c|}
\hline & Frequency & Percentage $(\%)$ \\
\hline \multicolumn{3}{|l|}{ Nationality } \\
\hline American (US) & 10 & 13.7 \\
\hline Canadian & 6 & 8.2 \\
\hline Chinese & 5 & 6.8 \\
\hline French & 4 & 5.5 \\
\hline German & 7 & 9.6 \\
\hline Indian & 7 & 9.6 \\
\hline Italian & 2 & 2.7 \\
\hline Malaysian & 9 & 12.3 \\
\hline Russian & 2 & 2.7 \\
\hline Saudi Arabian & 8 & 11.0 \\
\hline Singaporean & 1 & 1.4 \\
\hline South Korean & 6 & 8.2 \\
\hline Spanish & 4 & 5.5 \\
\hline Vietnamese & 2 & 2.7 \\
\hline Total & 73 & 100.0 \\
\hline \multicolumn{3}{|l|}{ Gender } \\
\hline Female & 55 & 75.3 \\
\hline Male & 18 & 24.7 \\
\hline Others & - & - \\
\hline Total & 73 & 100.0 \\
\hline \multicolumn{3}{|l|}{ Degree programme } \\
\hline Arts & 15 & 20.5 \\
\hline Business & 11 & 15.1 \\
\hline Dentistry/Medicine & 23 & 31.5 \\
\hline Engineering & 7 & 9.6 \\
\hline Geography & 3 & 4.1 \\
\hline Pure Sciences & 14 & 19.2 \\
\hline Total & 73 & 100.0 \\
\hline \multicolumn{3}{|l|}{ Level of study } \\
\hline Year 1 & 19 & 26.0 \\
\hline Year 2 & 27 & 37.0 \\
\hline Year 3 & 15 & 20.6 \\
\hline Year 4 and above & 12 & 16.4 \\
\hline Total & 73 & 100.0 \\
\hline \multicolumn{3}{|l|}{ Student status } \\
\hline Full-time & 61 & 83.6 \\
\hline Visiting/exchange & 12 & 16.4 \\
\hline Total & 73 & 100.0 \\
\hline
\end{tabular}

thus the final analysis compared respondents categorised as Europeans, North Americans, and Asians. Despite being coarser than nationality, the continent dimension would nevertheless still enable us to investigate similarities and differences across different groups of international students.

In the qualitative part of our study, we used thematic analysis on respondents' suggestions for improvement by coding their open-ended responses and identifying 
emerging themes. Based on Miles, Huberman, and Saldaña (2014), codes can be described as labels or keywords that assign meaning to descriptive or inferential information gathered in a study. Since our open-ended section was intended to produce all possible suggestions on how the host institution can improve peer learning experience for international students, we adopted the grounded approach advocated by Glaser and Strauss (1967) whereby no pre-coding was done until all data were collected. This approach to coding allowed us to unearth any unforeseen challenges encountered by the respondents, as well as their possible solutions.

Finally, we integrated our quantitative and qualitative data through methodological triangulation. According to Denzin (1989), this method facilitates validation of results by comparing data sourced from the same set of respondents using different data collection approaches. Particularly in the present case where the sample size was small, triangulating the quantitative data and open-ended responses would lend strength to our analysis and discussion (Tashakkori and Teddlie 2000), as elaborated later in the paper.

\section{Quantitative results}

The overall median values, as well as medians for the three sub-groups, are presented in Table 2. The $m_{0}$ scores represent the overall response of the total sample while similarities and differences among European, North American, and Asian respondents can be determined by comparing $m_{1}, m_{2}$, and $m_{3}$ scores. These results are discussed as follows.

\section{Usage rate}

Based on the overall medians, the most utilised type of peer learning among the respondents appears to be cooperative learning $\left(\mathrm{Q} 2: m_{0}=4.00\right)$, followed by collaborative learning $\left(\mathrm{Q} 3: m_{0}=3.00\right)$, and finally peer tutoring $\left(\mathrm{Q} 1: m_{0}=2.50\right)$. The popularity of cooperative learning could be a result of its more flexible approach than peer learning, allowing students to work together in a team and holding them collectively and individually accountable for their work. On the other hand, the low usage of peer tutoring is likely due to its formal nature, where one student must first be appointed as a mentor so that knowledge sharing can occur by way of peer-led tutorials.

For peer tutoring (Q1), the median reported by the Europeans is $m_{1}=3.00$, compared to North Americans $m_{2}=4.00$, and Asians, $m_{3}=2.00$. Taken together with the medians for cooperative learning $\left(\mathrm{Q} 2: m_{1}=3.00, m_{2}=5.00, m_{3}=4.00\right)$ and collaborative learning $\left(\mathrm{Q} 3: m_{1}=3.00, m_{2}=4.00, m_{3}=3.00\right)$, it may be said that the North American group tend to use all three types of peer learning to a higher degree than the other two groups. The scores also suggest that peer tutoring is more popular among European respondents than the Asians, which could mean that the former are relatively more comfortable with a formalised approach to peer learning than the latter.

\section{Current practices}

For current practices, the overall medians suggest that the respondents generally have a positive experience of current peer learning practices in this university. Specifically, they have quite a high regard for their professors' active role $\left(\mathrm{Q} 7: m_{0}=4.00\right)$ and the 
Table 2. Median values.

\begin{tabular}{|c|c|c|c|c|}
\hline & $\begin{array}{l}\text { Overall } \\
\quad\left(m_{0}\right)\end{array}$ & $\begin{array}{l}\text { Europeans } \\
\quad\left(m_{1}\right)\end{array}$ & $\begin{array}{l}\text { N. Americans } \\
\qquad\left(m_{2}\right)\end{array}$ & $\begin{array}{c}\text { Asians } \\
\left(m_{3}\right)\end{array}$ \\
\hline \multicolumn{5}{|l|}{ Usage rate } \\
\hline Q1. Peer tutoring & 2.50 & 3.00 & 4.00 & 2.00 \\
\hline Q2. Cooperative learning & 4.00 & 3.00 & 5.00 & 4.00 \\
\hline Q3. Collaborative learning & 3.00 & 3.00 & 4.00 & 3.00 \\
\hline \multicolumn{5}{|l|}{ Theme/Statement } \\
\hline $\begin{array}{l}\text { Q4. Peer learning is a significant component } \\
\text { of teaching and learning in my } \\
\text { programme here }\end{array}$ & 3.00 & 2.00 & 4.00 & 3.00 \\
\hline $\begin{array}{l}\text { Q5. I'm given enough opportunities to } \\
\text { demonstrate my knowledge and } \\
\text { leadership skills among my peers }\end{array}$ & 3.50 & 3.00 & 5.00 & 3.50 \\
\hline $\begin{array}{l}\text { Q6. There is a conducive environment for } \\
\text { peer learning in my programme }\end{array}$ & 4.00 & 3.00 & 5.00 & 4.00 \\
\hline $\begin{array}{l}\text { Q7. My professors encourage and facilitate } \\
\text { peer learning in their courses }\end{array}$ & 4.00 & 3.00 & 4.50 & 4.00 \\
\hline $\begin{array}{l}\text { Q8. In this university, peer learning is } \\
\text { supported with adequate technology and } \\
\text { infrastructure }\end{array}$ & 3.00 & 2.00 & 4.00 & 3.00 \\
\hline \multicolumn{5}{|l|}{ Outcomes } \\
\hline $\begin{array}{l}\text { Q9. Peer learning has helped me to increase } \\
\text { my academic performance in this } \\
\text { university }\end{array}$ & 4.00 & 3.00 & 5.00 & 4.00 \\
\hline $\begin{array}{l}\text { Q10. I have been able to adjust more easily } \\
\text { to the learning environment here because } \\
\text { of peer learning }\end{array}$ & 3.00 & 3.00 & 4.50 & 3.00 \\
\hline $\begin{array}{l}\text { Q11. Peer learning enables me to play my } \\
\text { role as an international student to } \\
\text { improve learning for myself and my peers }\end{array}$ & 4.00 & 3.00 & 4.00 & 4.00 \\
\hline \multicolumn{5}{|l|}{ Challenges } \\
\hline $\begin{array}{l}\text { Q12. I find peer learning here very } \\
\text { challenging because of language and } \\
\text { communication barriers }\end{array}$ & 2.00 & 3.00 & 2.00 & 2.50 \\
\hline $\begin{array}{l}\text { Q13. Cultural/religious factors make it } \\
\text { difficult for me to participate in peer } \\
\text { learning at this university }\end{array}$ & 2.00 & 2.00 & 1.50 & 2.00 \\
\hline $\begin{array}{l}\text { Q14. In group assignments, disagreements/ } \\
\text { arguments among my group members } \\
\text { jeopardise the success of the assignments }\end{array}$ & 2.00 & 2.00 & 2.00 & 2.00 \\
\hline $\begin{array}{l}\text { Q15. My team members are not committed } \\
\text { and rarely come prepared for team } \\
\text { projects }\end{array}$ & 2.50 & 3.00 & 2.00 & 2.00 \\
\hline $\begin{array}{l}\text { Q16. My team members do not respect my } \\
\text { opinions }\end{array}$ & 1.50 & 2.00 & 1.00 & 2.00 \\
\hline
\end{tabular}


Table 2. Continued.

\begin{tabular}{lcccc}
\hline & $\begin{array}{c}\text { Overall } \\
\left(m_{0}\right)\end{array}$ & $\begin{array}{c}\text { Europeans } \\
\left(m_{1}\right)\end{array}$ & $\begin{array}{c}\text { N. Americans } \\
\left(m_{2}\right)\end{array}$ & $\begin{array}{c}\text { Asians } \\
\left(m_{3}\right)\end{array}$ \\
\hline $\begin{array}{l}\text { Coping strategies } \\
\text { Q17. My team members prefer to let our } \\
\text { team leaders settle our disagreements/ } \\
\text { arguments }\end{array}$ & 4.00 & 4.00 & 2.50 & 4.00 \\
$\begin{array}{l}\text { Q18. My team members seek intervention } \\
\text { by the professors to resolve outstanding } \\
\text { issues faced in our group assignments }\end{array}$ & 2.00 & 1.00 & 2.50 & 2.00 \\
$\begin{array}{l}\text { Q19. To help improve our teamwork, my } \\
\text { team members socialise together outside } \\
\text { the classroom }\end{array}$ & 3.00 & 2.00 & 4.00 & 3.00 \\
\hline
\end{tabular}

conducive environment created by the university $\left(\mathrm{Q} 6: m_{0}=4.00\right)$. The respondents also appear to be reasonably satisfied with the opportunities to demonstrate their knowledge and leadership skills $\left(\mathrm{Q} 5: m_{0}=3.50\right)$. That said, their evaluation of peer learning as a component of the overall T\&L practices implemented in their respective programmes warrants some attention. The median score on Q4 $\left(m_{0}=3.00\right)$ suggests that more can be done in this university to increase the adoption of peer learning as a T\&L method, alongside other methods such as normal lectures and individual assignments. Additionally, there may also be room for improvement as far as technological and infrastructural support is concerned (Q8: $\left.m_{0}=3.00\right)$.

Consistently for all five statements in this section, the North American group gave the highest medians, followed by the Asians, while the lowest were given by Europeans. From this, we deduce that most of the North Americans tend to have very positive experience of current peer learning practices in this university whereas the Europeans seem much less positive. The most striking difference between the North Americans and the other two groups are in terms of how they maximise the opportunities to demonstrate their knowledge and leadership skills, where the North Americans gave a far higher score than Europeans and Asians (Q5: $\left.m_{1}=3.00, m_{2}=5.00, m_{3}=3.50\right)$. This finding implies that while some international students are confident enough to demonstrate their skills and knowledge voluntarily, others may need more encouragement and teacher intervention. Furthermore, on the significance of peer learning as a component of overall T\&L methods $\left(\mathrm{Q} 4: m_{1}=2.00\right)$ and technological and infrastructural support $\left(\mathrm{Q} 8: m_{1}=2.00\right)$, the European scores reflect a moderately negative experience. This indicates that some expectations of European students concerning T\&L and its facilities may not be adequately met in this university.

\section{Outcomes}

Here the evidence suggests that the respondents have generally enjoyed positive outcomes from their peer learning experience in this institution. Mostly peer learning enables them to execute their role as international students in improving learning for themselves and their peers $\left(\mathrm{Q} 11: m_{0}=4.00\right)$ and enhances their academic performance (Q9: $\left.m_{0}=4.00\right)$. However, the positive effect of peer learning on the students' ability to adjust to the foreign learning environment (Q10: $\left.m_{0}=3.00\right)$ is relatively 
less. We believe this pattern reflects the lower overall usage rate of peer tutoring in this university $\left(\mathrm{Q} 1: m_{0}=2.50\right)$, and some weaknesses in technological and infrastructural support $\left(\mathrm{Q} 8: m_{0}=3.00\right)$, as reported earlier.

North American respondents generally reported higher scores on all three outcomes compared to the other two samples. This suggests that out of the three groups of respondents, the North Americans appear to be most satisfied in terms of what they have gained from peer learning in this university. Compared to the Europeans and Asians, North American respondents have a better perception of the effect of peer learning on their ability to adjust to the foreign environment (Q10: $\left.m_{1}=3.00, m_{2}=4.50, m_{3}=3.00\right)$, as well as its effect on their academic performance (Q9: $\left.m_{1}=3.00, m_{2}=5.00, m_{3}=4.00\right)$. North Americans and Asians also have a more positive view of peer learning as a platform for them to execute their role and improve learning for themselves and their peers (Q11: $\left.m_{1}=3.00, m_{2}=4.00, m_{3}=4.00\right)$.

\section{Challenges}

The overall medians suggest that our respondents generally do not encounter major problems in their peer learning experience in this university. In particular, issues concerning respect for opinion $\left(\mathrm{Q} 16: m_{0}=1.50\right)$ appear to be very small. Our respondents also do not consider language and communication $\left(\mathrm{Q} 12: m_{0}=2.00\right)$, cultural or religious factors $\left(\mathrm{Q} 13: m_{0}=2.00\right)$, and conflicts among team members (Q14: $\left.m_{0}=2.00\right)$ to be major barriers in their peer learning process. Comparatively, however, the commitment and dedication of team members $\left(\mathrm{Q} 15: m_{0}=2.50\right)$ top the list of concerns. This implies some issues associated with incompatible learning priorities between the respondents and their team members, since the level of commitment that a student demonstrates toward a particular learning task is often related to the level of importance s/he attaches to it.

On all five related statements, North American respondents seem to experience less challenges in peer learning than the other two groups. Their scores on team members' respect $\left(\mathrm{Q} 16: m_{2}=1.00\right)$, and commitment $\left(\mathrm{Q} 15: m_{2}=2.00\right)$, as well as language and communication barriers $\left(\mathrm{Q} 12: m_{2}=2.00\right)$ are clearly lower than those given by European and Asian respondents. For the Asian group, language and communication issues (Q12: $\left.m_{3}=2.50\right)$ appear to be their greatest concern, followed by team members' commitment (Q15: $\left.m_{3}=2.00\right)$, conflicts among team members (Q14: $\left.m_{3}=2.00\right)$, and cultural and religious factors $\left(\mathrm{Q} 13: m_{3}=2.00\right)$. In contrast, the Europeans seem to be challenged mainly by team members' commitment (Q15: $\left.m_{1}=3.00\right)$ as well as language and communication barriers (Q12: $\left.m_{1}=3.00\right)$, while cultural and religious factors $\left(\mathrm{Q} 13: m_{1}=2.00\right)$ and conflicts among team members $\left(\mathrm{Q} 14: m_{1}=2.00\right)$ pose less problems for them. Comparing the scores on team members' commitment (Q15: $\left.m_{1}=3.00, m_{2}=2.00, m_{3}=2.00\right)$, it would appear that the possibility of incompatible learning priorities between the respondents and their team members could be greater for European respondents than for the other two groups.

\section{Coping strategies}

As indicated in Table 2, the most popular coping strategy seems to be team leadership (Q17: $\left.m_{0}=4.00\right)$, whereas seeking teacher intervention (Q18: $\left.m_{0}=2.00\right)$ is the least popular. From this, we deduce that while the respondents acknowledge the role of 
academics as motivators and facilitators in the peer learning process $\left(\mathrm{Q} 7: m_{0}=4.00\right)$, in practice, peer learning teams rarely consult with their professors when they encounter problems and prefer to find the solutions themselves. Instead, they prefer to rely on their own team leaders to provide solutions to the problems, thus emphasising the importance of peer leadership in learning. However, the respondents seem uncertain about the benefits of socialising with team mates outside the classroom (Q19: $m_{0}=3.00$ ), suggesting that they generally do not participate much in informal socialisation processes occurring in their habitus.

According to European and Asian respondents, the most popular coping strategy adopted by their team members is team leadership (Q17: $\left.m_{1}=4.00, m_{3}=4.00\right)$. This is followed by socialising outside the classroom (Q19: $\left.m_{1}=2.00, m_{3}=3.00\right)$, and seeking teacher intervention $\left(\mathrm{Q} 18: m_{1}=1.00, m_{3}=2.00\right)$. On the other hand, the North Americans' experience is such that socialising outside the classroom (Q19: $\left.m_{2}=4.00\right)$ is more preferred than teacher intervention $\left(\mathrm{Q} 18: m_{2}=2.50\right)$ and team leadership (Q17: $m_{2}=2.50$ ). These figures suggest that, when faced with learning problems, North American respondents prefer to find solutions through informal processes beyond the classroom. In contrast, the other two groups seem to depend on a more systematic approach decided by their team leaders.

\section{Qualitative results}

Out of the total 73 respondents, only 25 chose to complete the open-ended section on suggestions for improvement. As shown in Table 3, these 25 respondents were either Europeans or Asians, whereas the North Americans have completely abstained.

Using codes to categorise the responses into broader themes, we identified four areas of improvement suggested by both European and Asian respondents, namely: (1) course structure, (2) teacher intervention, (3) cultural and religious inclusiveness, and (4) language and communication skills. We also detected three additional areas suggested by the Asian group: (1) social events, (2) home country participation, and (3) learning space. These seven areas of improvement are captured in the last column of Table 3, with direct quotations from the respondents shown in the middle column.

\section{Triangulation of results}

We then triangulated our qualitative and quantitative results to check for the validity of our findings. Based on the outcome, we find several similarities and differences across groups of international students at this university, in three key aspects: (1) types, styles, and outcomes of peer learning, (2) conflicts arising from incongruent learning priorities, and (3) types of institutional support needed.

\section{Modes, styles, and outcomes of peer learning}

First and foremost, our findings affirm the work by Parr and Townsend (2002), which clearly distinguished among various modes and styles of peer learning. Our quantitative data indicate that the three groups of respondents surveyed in this study not only demonstrated different usage rates of peer tutoring, cooperative learning, and collaborative learning, they also showed a varied preference for formal and informal 
Table 3. Open-ended responses.

Respondent

No. (RN)

Direct quotations

Codes/emerging Themes

Sub-sample: Europeans

4

5

6

8

15

19

20
Encourage group discussions not only after class, but also during lecture, to enable greater student participation and involvement

Include group work in assignments and ensure that every group is made up of local and foreign students

The climate for teamwork in this university isn't good. Universities in other countries have more structure in their programmes which encourages teamwork. Here, the students seem to hate teamwork and do as little as possible in group discussions

In the classroom, foreign students may feel insecure about speaking up in front of the natives. Lecturers should invite them explicitly to answer questions, instead of throwing the questions generally to the whole class

Random assignment of groups in a big class throws everyone in the deep end. It's better if groups are assigned formally by professors or programme coordinators

Certain courses allow students to form project teams themselves. That's fine when you already have friends, but it may cause foreign students to be left out. It helps a lot if the professors ask that each group must include both local and international students

Local students prefer to stick to their own friends and don't like to integrate with foreign students. Because my English isn't very good, I had difficulty communicating with them. I wish I was given enough opportunity to improve my English and contribute my ideas to the team

There should be group discussions in the classroom itself, instead of asking the students to do it entirely in their own time
Course structure Teacher intervention

Course structure Teacher intervention

Course structure

Cultural/religious inclusiveness

Teacher intervention

\section{Course structure Teacher} intervention

Teacher intervention

Cultural/religious inclusiveness Language and communication skills

\section{Course structure Teacher} intervention 
Table 3. Continued.

Respondent

No. (RN)

Direct quotations

Codes/emerging Themes

21

25

Sub-sample: Asians
Local students, especially in the last year of study, already have their own set of friends in the classroom. I don't feel comfortable with them and prefer to work with other international students. We are all in the same situation and it helps to socialise together

Integrate peer learning activities more into the curriculum. There should be more group assignments and greater encouragement by the professors

3

Students with language or communication problems should be given English lessons

Groups for team projects should be assigned by professors rather than have students form their own groups. This way, it's more helpful for international students who don't have any friends in the class

My class size is too big. This makes it difficult to have group discussions in the classroom

Within the campus compound, facilities for Muslim students are insufficient, particularly prayer room and halal food supply. It's difficult for us to participate in group discussions after class if the meeting venue doesn't have any prayer facilities and there's no halal food available. The university should step up its efforts to understand and serve the needs of different ethnic minorities that make up the international student population

There should be cross-cultural management courses for all students. Organise more social events that can bring local and international students together
Cultural/religious inclusiveness

Course structure Teacher intervention

Language and communication skills Course structure

Teacher intervention

Course structure Learning space

Cultural/religious inclusiveness

Cultural/religious inclusiveness Course structure Social activities 
Table 3. Continued.

Respondent

No. (RN)

Direct quotations

Codes/emerging Themes

28

37

41

51

56

57

58

59

60
In some courses, teams are assigned by the professor. So he/she should play a more active role to ensure that team members are comfortable with one another. Otherwise allow students to choose their own team members

Assign more group projects than individual essays

There is a lot of prejudice among local students toward us from Asia. They look up to American and Canadian students but look down on us. Maybe if there are more activities to create awareness among local students about Asian success stories, things can be improved

Discussion groups should be made smaller. That will give everyone more opportunities to speak up and contribute their ideas

There should be more activities to help us understand cultural differences among students of various nationalities

Allocate more learning spaces throughout the campus where students can interact freely without being told off

It would be good if we could have teaching assistants who are our own senior students. They understand our situation and will be able to give practical advice about adapting to the new environment here

Encourage more peer tutoring in practice, such as laboratory and clinical work. At the moment, there are good peer learning activities for theoretical discussions but not enough in the practical components of the programme

In my programme, we mostly have cooperative learning among our own classmates. Personally I would like to have more peer tutoring, especially from sophomores, because they have a higher level of expertise than freshmen

\section{Teacher intervention}

Course structure

Cultural/religious inclusiveness Social activities Home country participation

\section{Course structure Teacher intervention}

\section{Cultural/religious inclusiveness Social activities}

Learning space

\section{Course structure}

Course structure

Course structure 
Table 3. Continued.

Respondent

No. $(\mathrm{RN}) \quad$ Direct quotations Codes/emerging Themes

63

Local students here don't appreciate the opportunity to work with international students. But I think the professors and tutors can improve the situation by explaining to them the benefits of international education and organising the course in such a way that local and international students can learn from one another
Cultural/religious inclusiveness Course structure Teacher intervention

ways of solving learning-related problems. From the median comparisons, we are able to deduce that North American and Asian students tend to have an equal tendency for both formal and informal peer learning compared to Europeans, who seem to prefer a more formal and structured approach. This deduction is coherent with our quantitative findings on peer learning outcomes, which show that the perception of European respondents is less positive than that of North Americans and Asians, both academically and socially. We believe that since the European group shows a greater tendency for formal types and styles of peer learning, they are likely to miss out on the advantages of informal approaches through socialisation processes that occur beyond the classroom. In turn, this is reflected in their less positive perception of the outcomes of peer learning implemented in this university.

In the qualitative section, responses related to course structure and social events provide further support for this deduction. For example, while most of the European respondents (R1, R4, R5, R8, R20, and R25) emphasised the importance of formal classroom-based activities, a high number of Asians (R26, R27, R41, R56, and R63) have argued for more inclusive social activities outside the classroom that would allow them to adjust better to the host environment.

\section{Conflicts arising from incongruent learning priorities}

Our findings are consistent with the earlier discussed studies by Naykki et al. (2014) and O'Reilly, Hickey, and Ryan (2013), which suggested that incongruent learning priorities between local and foreign students, and indeed among different groups of international student, are some of the key challenges in international higher education. From our quantitative section, we find some indication of conflicting learning priorities between our respondents (especially Europeans) and their team members, which could also have given them the impression that their peers were not committed to group projects. Qualitative responses (R3, R5, R19, and R27) related to language and communication skills, as well as course structure, gave some additional evidence for this observation. In particular, the response given by R19: ‘ ... Because my English isn't very good, I had difficulty communicating with them. I wish I was given enough opportunity to improve my English and contribute my ideas to the team', implies that 
there were conflicts between this respondent and other members of her team because improving communication skills was a priority for her but not for the others.

\section{Types of support and intervention needed for effective peer learning}

Mainly, our findings demonstrate that some groups of international students are more dependent than others on various forms of support and intervention to create a conducive environment which can improve their peer learning experience. Whereas North American students appear to have the confidence and skills to build the social relationships important for learning, Asians and Europeans seem to need greater systematic inputs and interventions from key players in the host environment. This is evident from our quantitative results on current practices and challenges, which suggest that both European and Asian students require a substantial amount of support to improve their language, communication, and social skills. In the case of European students, creating a more favourable learning environment which includes better use of technology and physical infrastructure also appears to be important.

Our qualitative findings lend additional evidence for the importance of systematic support to improve the peer learning experience of European and Asian students. Themes related to course structure, teacher intervention, language and communication skills, religious and cultural inclusiveness, social activities, and learning space all indicate various forms of intervention needed by these two groups of international students which should be institutionalised and cascaded to all levels of the university. Without adequate institutional, teacher and peer support, Asian and European students face some difficulty to participate in group work, which may have resulted in their poorer utilisation of peer learning and lower learning outcomes than the North Americans'. According to Charles-Toussaint and Crowson (2010), this situation can be further worsened if there is a possible threat of prejudice from local students, as implied by R19: 'Local students prefer to stick to their own friends and don't like to integrate with foreign students', and R41:

There is a lot of prejudice among local students toward us from Asia. They look up to American and Canadian students but look down on us. Maybe if there are more activities to create awareness among local students about Asian success stories, things can be improved.

However, it should be noted that local actors are not the only parties who can play a role in reducing this risk of prejudice. From the response given by R41, we deduce that home country agencies such as international student associations, embassies, and trade associations are also called to play their part.

\section{Discussion}

From the overall quantitative results, we are able to conclude that international students in this university generally enjoy their peer learning experience here. Consistent with social learning and constructivism theories (Bandura 1977; Fernández et al. 2015; Hall and Jaugietis 2010; Topping \& Ehly, 2001), our respondents demonstrate an enhanced learning experience when they are placed in a learning environment which encourages social exchange and interactions, especially among peers. In this regard, peer learning has helped to expand their role and horizon as international 
students, contributed to their ability to adapt to the foreign environment, and improved their academic performance. Although the low usage rate of peer tutoring deserves a further introspection, the students have nevertheless benefited from a relatively high utilisation of cooperative and collaborative forms of peer learning, which are less structured and allow for greater flexibility in the learning process (Jacobs, Hurley, and Unite 2008; McGuire 2006; Parr and Townsend 2002). The results also reveal that international students in this host institution generally do not face major difficulties in their peer learning activities, either in communication and social aspects or from the perspective of infrastructure and technology. Overall, it is clear that current practices implemented by this institution have served its international students well thus far, as reflected by its past international reputation and ranking.

However, recent trends in student mobility suggest that international students are now looking for the best learning experiences which not only optimise their employability and career options, but can also cater for the massive diversity in the international student population (de Wit 2010; Hawawini, 2011). This is captured in our study through the comparison of medians among the three groups of international students, as well as the open-ended suggestions given by some of the respondents. Essentially, our findings emphasise the importance of looking past overall scores and gearing up efforts to understand the diverse needs of different groups of international students located in a particular learning environment. From the perspective of European international higher education (European Commission 2010; Olcott 2009; Teichler 2009; Zgaga 2006), this case study has highlighted some challenges faced by Europeans studying in European universities outside their home countries. Despite the short geographical distance between Ireland and other European nations, gaps in language, communication, culture and learning priorities are demonstrated in this study as issues worthy of further investigation.

The areas of improvement recommended by our respondents have a considerable impact on the host institution, as well as its academic and administration staff, since they involve better structuring of programmes and courses, teacher intervention and supervision, more inclusive socio-cultural events, and properly designed learning spaces. Our study also indicates that the learning experience and outcomes of international students are dependent not only on the host university, but also the students' home agencies such as their embassy, media relations, trade associations, and education providers. The participation of these agencies is essential to fill in existing knowledge gaps among local students about socio-economic developments and opportunities in other countries. We believe that with increased knowledge of current progress achieved outside the host country, the likelihood of friction between international and local students (Keane 2009; Lee and Rice 2007; Sherry, Thomas, and Chui 2009) can be substantially reduced, leading to greater readiness for diversity and inclusion. On a broader scale, active interactions between host universities and international students, as well as their home agencies, can make up a part of the CIE course proposed by O'Sullivan (2008).

\section{Limitations and suggestions for future research}

A key constraint of this study was our small sample, thinly spread over 14 nationalities. Thus, we were unable to analyse the respondents based on nationality or citizenship; rather it had to be done using the coarser dimension of the continent. The small 
sample size also prevented us from applying more sophisticated quantitative techniques such as ANOVA or multi-level analysis (MLA), which would have given us a deeper understanding of the students' peer learning experience in this university. For example, with a bigger sample, MLA would have enabled us to compare students of a particular nationality studying in various degree programmes at various levels of their study.

Another limitation concerns sample representativeness. Our attempts to seek detailed information on the overall population of international students in this university were unsuccessful. As a result, we were unable to deduce the representativeness of our sample in relation to the overall international student population at the institution. Finally, being an exploratory case study, the findings presented in this paper are not necessarily generalisable to other universities in Ireland. Since students' experiences and perceptions are affected by many factors in their learning environment or habitus, studies in other universities may produce different results. Nevertheless, we expect to be able to resolve these limitations in future research using a bigger data set involving other Irish universities.

\section{Conclusion}

Starting from the assumption that the role of peers is critical in learning, this study aimed to investigate the topic of peer learning in the context of international higher education, focusing on the experience of international students in a leading Irish university. Our findings suggest that, while the overall experiences and perceptions appear to be positive, there are unique differences among individual groups of international students which affect their learning processes and outcomes. For some, specific challenges in peer learning seem to rise as a result of language, communication, and socio-cultural factors, as well as incongruent learning priorities, which require adequate attention from the host institution, teachers, and other local actors.

However, findings of the study also suggest that local actors are not the only stakeholders responsible for international students' learning experiences and outcomes. Instead, greater participation by international student representatives and their home agencies is also essential to help improve understanding and appreciation of diversity in a cross-cultural learning environment. To this end, we call for stronger and more effective engagement involving the various parties, supported with an open communication channel with continuous feedbacks and follow-ups.

\section{Funding}

This work was supported by Ministry of Education Malaysia.

\section{Notes on contributors}

Aida Idris is an Associate Professor at the Faculty of Business and Accountancy, University of Malaya (UM), Kuala Lumpur. She was Visiting Professor at the School of Education, Trinity College Dublin from 2015 to 2017, and is currently the Deputy Executive Director of AsiaEurope Institute, UM.

Georgeta Ion holds a PhD in Educational Sciences and currently serves as an Associate Professor at the Department of Applied Pedagogy, Universitat Autònoma de Barcelona. 
Aidan Seery is an Assistant Professor at the School of Education, Trinity College Dublin, and a member of its Cultures, Academic Values and Education Research Centre. He is also presently the university's Senior Tutor.

\section{References}

Andrade, M. S. 2006. "International Students in English Speaking Universities." Journal of Research in International Education 5 (2): 131-154.

Bandura, A. 1977. Social Learning Theory. New York: General Learning Press.

Bartram, B. 2008. "Supporting International Students in Higher Education: Constructions, Culture and Clashes." Teaching in Higher Education 13 (6): 657-668.

Brown, L., and I. Holloway. 2008. "The Initial Stage of the International Sojourn: Excitement or Culture Shock?" British Journal of Guidance \& Counselling 36 (1): 33-49.

Bryant, L. H. 2011. "The Structure of Mixed Method Studies in Educational Research: A Content Analysis." Journal of Research in Education 22 (1): 82-99.

Burns, R. 2000. Introduction to Research Methods. London: Sage.

Campbell, A. 2010. "Developing Generic Skills and Attributes of International Students: the (Ir)relevance of the Australian University Experience." Journal of Higher Education Policy and Management 32 (5): 487-497.

Campbell, N. 2012. "Promoting Intercultural Contact on Campus: A Project to Connect and Engage International and Host Students." Journal of Studies in International Education 16 (3): 205-227.

Cantor, N. 2004. "Introduction." In Defending Diversity. Affirmative Action at the University of Michigan, edited by P. Gurin, J. Lehman, and E. Lewis, 1-16. Ann Arbor: University of Michigan Press.

Central Statistics Office. 2016. Census 2016 Reports. http://www.cso.ie/en/census/ census2016reports/.

Chapman, D., and R. Sakamoto. 2011. "The Future of Cross-border Partnerships in Higher Education." In Cross-border Partnership in Higher Education. Strategies and Issues, edited by R. Sakamoto and D. Chapman , 265-271. London: Routledge.

Charles-Toussaint, G. C., and H. M. Crowson. 2010. "Prejudice Against International Students: the Role of Threat Perceptions and Authoritarian Dispositions in US Students." Journal of Psychology 144 (5): 415-428.

Cohen, E. G., R. A. Lotan, and N. Holthuis. 1995. "Talking and Working Together: Conditions for Learning in Complex Instruction." In Restructuring Schools: Promising Practices and Policies, edited by M. T. Hallinan, 157-174. New York: Plenum Press.

Cohen, L., L. Manion, and K. Morison. 2000. Research Methods in Education. 5th ed. London: Routledge Falmer.

Denzin, N. K. 1989. The Research Act: A Theoretical Introduction to Sociological Methods. 3rd ed. New York: Prentice Hall.

de Wit, H. 2010. Internationalisation of Higher Education in Europe and its Assessment, Trends and Issues. The Hague: Nederlands-Vlaamse Accreditatieorganisatie (Accreditation Organisation of the Netherlands and Flanders).

Dunne, C. 2013. "Exploring Motivations for Intercultural Contact among Host Country University Students: An Irish Case Study." International Journal of Intercultural Relations 37: $567-578$.

Erichsen, E. A., and D. U. Bolliger. 2011. "Towards Understanding International Graduate Student Isolation in Traditional and Online Environments." Educational Technology Research and Development 59: 309-326.

European Commission. 2010. Lisbon Strategy Evaluation Document. Brussels. http://ec.europa. eu/ europe2020/pdf/lisbon_strategy_evaluation_en.pdf.

Evans, H. 2015. "International Postgraduate Students and Peer Learning." Journal of Pedagogic Development 5 (3): 1-23.

Evans, C., and K. Stevenson. 2011. "The Experience of International Nursing Students Studying for a PhD in the UK: A Qualitative Study." BMC Nursing 10: 11. http://www. biomedcentral.com/1472-6955/10/11. 
Faughey, D. 2016. Exploring what the Brexit vote means for education in the UK. International Education News. https://internationalednews.com/tag/brexit/.

Fernández, M., R. Wegerif, N. Mercer, and S. Rojas-Drummond. 2015. "Re-conceptualizing 'Scaffolding' and the Zone of Proximal Development in the Context of Symmetrical Collaborative Learning." Journal of Classroom Interaction 50 (1): 54-72.

Furnham, A. 2004. "Foreign Students' Education and Culture Shock." Psychologist 17 (1): 1619.

Glaser, B. G., and A. L. Strauss. 1967. The Discovery of Grounded Theory: Strategies for Qualitative Research. Chicago, IL: Aldine.

Hall, R., and Z. Jaugietis. 2010. "Developing Peer Monitoring Through Education.” Innovation in Higher Education 36: 41-52.

Hawawini, G. 2011. The Internationalization of higher Education Institutions: A Critical Review and a Radical Proposal, INSEAD Working Paper. http://www.insead.edu/facultyresearch/ research/doc.cfm?did=.

Huang, Y. 2012. "Transitioning Challenges Faced by Chinese Graduate Students." Adult Learning 23: 138-147.

IES. 2015. Mixed Methods In Education Research. IES Technical Working Group Meeting Summary. https://ies.ed.gov/ncer/whatsnew/techworkinggroup/pdf/MixedMethodsTWG.

Irish Independent. 2017. "Number of International Students Here Growing." December 11. https://www.independent.ie/irish-news/education/number-of-international-students-heregrowing-36396249.html.

Jacobs, G., M. Hurley, and C. Unite. 2008. "How Learning Theory Creates a Foundation for SI Leader Training." Journal of Peer Learning 1 (1): 6-12.

Keane, E. 2009. "'Frictional' Relationships ... Tension in the Camp: Focusing on the Relational in Under-represented Students' Experiences in Higher Education." Irish Educational Studies 28 (1): 85-102.

Keenan, C. 2014. Mapping Student-led Peer Learning in the UK. York: The Higher Education Academy. http://bit.ly/2oXbnhc.

Lee, J. J., and C. Rice. 2007. "Welcome to America?" International Student Perceptions of Discrimination. Higher Education 53: 381-409.

Lillyman, S., and C. Bennett. 2014. "Providing a Positive Learning Experience for International Students Studying at UK Universities: a Literature Review." Journal of Research in International Education 13 (1): 63-75.

McGuire, S. Y. 2006. "The Impact of Supplemental Instruction on Teaching Students how to Learn." New Directions for Teaching and Learning 10 (6): 3-11.

Miles, M. B., A. M. Huberman, and J. Saldaña. 2014. Qualitative Data Analysis: A Methods Sourcebook. 3rd ed. Los Angeles, CA: Sage.

Mittelmeier, J., B. Rienties, D. Tempelaar, and D. Whitelock. 2017. "Overcoming Cross-cultural Group Work Tensions: Mixed Student Perspectives on the Role of Social Relationships." Higher Education. doi:10.1007/s10734-017-0131-3.

Naykki, P., S. Jarvela, P. A. Kirschner, and H. Jarvenoja. 2014. "Socio-emotional Conflict in Collaborative Learning - A Process-oriented Case Study in a Higher Education Context." International Journal of Educational Research 68: 1-14.

OBHE. 2013. Horizon Scanning: What Will Higher Education Look Like in 2020? London: UK HE International Unit.

OECD. 2014. Education at a Glance 2014: OECD Indicators. http://www.oecd.org/edu/ Education-at-aGlance-2014.pdf.

Olcott, D. 2009. "Back to the UK Future." Perspective: Policy and Practice in Higher Education 13 (4): 98-103.

O’Reilly, A., T. Hickey, and D. Ryan. 2013. "Higher Education Professionals' Perspectives on International Student Experiences of Life and Learning in Ireland: a Qualitative Study." Irish Educational Studies 32 (3): 355-375.

O’Sullivan, M. 2008. "Comparative and International Education in Initial Teacher Education: An Irish Case Study." Irish Educational Studies 27 (3): 241-251.

Parr, J. M., and M. A. R. Townsend. 2002. "Environments, Processes, and Mechanisms in Peer Learning." International Journal of Educational Research 37: 403-423. 
QS World University Rankings. 2016/2017. http://www.topuniversities.com/qs-worlduniversity-rankings.

Sherry, M., P. Thomas, and W. H. Chui. 2009. "International Students: A Vulnerable Population." Higher Education 60: 33-46.

Tashakkori, A., and C. Teddlie. 2000. Mixed Methodology. Thousand Oaks, CA: Sage.

Teferra, D., and J. Knight. 2008. Higher Education in Africa: The International Dimension. Chestnut Hill, MA: Center for International Higher Education.

Teichler, U. 2009. "Internationalisation of Higher Education: European Experiences." Asia Pacific Education Review 10: 93-106.

Topping, K., and S. Ehly. 2001. "Peer-assisted Learning: A Framework for Consultation." Journal of Educational and Psychological Consultation 12 (2): 113-132.

University Times. 2017. "Brexit is 'Game on' and Irish Higher Education Needs to Prepare for the Challenge Ahead." April 1. http://www.universitytimes.ie/2017/04/brexit-is-game-onand-irish-higher-education-needs-to-prepare-for-the-challenge-ahead/.

Warring, S. 2010. "Facilitating Independence Amongst Chinese International Students Completing a Bachelor of Applied Business Studies Degree." Innovations in Education and Teaching International 47 (4): 379-392.

Webb, J., T. Schirato, and G. Danaher. 2002. Understanding Bourdieu. Crows Nest: Allen \& Unwin.

Williamson, S., and L. Paulsen-Becejac. 2015. "The Impact of Peer Learning Within a Group of International Post-Graduate Students - A Pilot Study." Athens Journal of Education 10: 3354.

Yeh, C. J., and M. Inose. 2003. "International Students' Reported English Fluency, Social Support Satisfaction and Social Connectedness as Predictors of Acculturative Stress." Counselling Psychology Quarterly 16 (1): 15-28.

Zgaga, P. 2006. "External Dimension' of the Bologna Process: First Report of the Working Group on the External Dimension of the Bologna Process." http://www.bolognaoslo.com/ expose/global/ download.asp?id=28\&fk=11\&thumb. 